\title{
How to Survive the Present while Preparing for the Future: A Research Library Strategy
}

\section{Eldred Smith and Peggy Johnson}

\begin{abstract}
Research librarians are looking for and experimenting with strategies to cope with declining resources, increasing obligations, and the impact of new electronic information technology. This paper urges concerted action on the part of the entire research library community, in which ownership is traded for access and institutional competition for cooperation, so that the research library will not simply survive but reshape itself to contribute to a new world of scholarly communication. It suggests concrete steps that can be taken to achieve these goals.
\end{abstract}

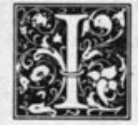

$t$ is widely recognized that the research library is in serious difficulty. Expected to do more and more with less and less, it appears to be in a downward spiral of deterioration moving toward collapse, and there seems to be little that can be done about it. But is this, in fact, the case? A long-term solution to the library's crisis is beginning to emerge, as the research/higher education community takes advantage of the new information technology, transforming scholarly communication from a print-based to an electronic-based system.

Unfortunately, this solution is probably several decades away. Consequently, the critical issue for research librarians is to develop a strategy that will preserve the research library through its present difficulty, and at the same time begin to reshape it for a radically different future. Such a strategy is now, both technologically and organizationally, within the grasp of the research library community.
Much has been written and continues to be written about the stringent times in which research libraries are operating. Three pervasive causes are identified consistently: rising costs of materials and services, shrinking budgets, and the impact of new technologies for performing tasks and handling information. All contribute to the problems that face research libraries today. Nor is it likely that any of these problems will become either less significant or less ubiquitous. The financial situation will not substantially improve. The dollar remains unsteady on the international market, and costs of both monographs and serials continue to increase in excess of inflation. At the same time, the volume of scholarly publication expands exponentially, as it has for the past five hundred years.

Although all segments of the economy are in difficulty, the challenges confronting higher education are particularly severe and likely to be long-lasting. Even the richest and most well-established universities are in trouble and are forced 
to eliminate programs, to downsize, and to rebuild infrastructure with reduced resources. ${ }^{1}$ In more and more institutions, the library's allocation, which has often been protected in past times of difficulty, is now retrenched along with others. The acquisition budget may still be sacrosanct in many universities, but libraries are expected increasingly to maintain it themselves by cutting elsewhere within their own resources. ${ }^{2}$

At the same time that their purchasing power is shrinking, research libraries must acquire and provide access to a rapidly expanding amount of nontraditional formats and sources of information, further complicating an already complex budgetary situation. Information that is stored, managed, and delivered by computer is becoming a standard and increasing-and increasingly expensive-part of research library programs.

\section{A long-term solution to the library's crisis is beginning to emerge, as the research/higher education community takes advantage of the new information technology, transforming scholarly communication from a print-based to an electronic-based system.}

How is the research library to cope with this array of problems? How will it find its way between the Scylla of budgetary crisis and the Charybdis of the new technology? Will this technology prove to be simply an additional burden, or will it, as many have hoped, offer a means by which research libraries can ultimately resolve their difficulties? These are the questions that research librarians are asking themselves and each other. ${ }^{3}$

An answer, at least for the long term, is beginning to emerge. Recently a credible snapshot of the future has been provided by the report of the Task Force on Electronic Information Systems of the American Physical Society (APS). The report, the result of three years of intensive investigation, asserts that a complete, generally accessible, international electronic database of science is not only possible and desirable, but "probably inevitable . . . by 2020."4

The database would replace and improve upon the present system of print publication for science. It would include all authenticated (i.e., reviewed and edited) research. It would also contain "various forms of less formal literature, like preprints in a 'prepublication phase,' comments and discussion on the published literature, and a variety of possible forums" - the vast and continually growing body of prepublished and unreviewed works, the so-called gray literature, whose limited availability has long been one of the most critical information-access problems for the scientific community. $^{5}$

The database would be fully indexed, utilizing both human and electronic capabilities. "Among the variety of algorithms that are possible, some will involve indexing documents by bibliographic information, descriptors, keywords or symbols, and citations-indexing that will be done partially by computer and partially with human assistance from editors, authors, other experts in the field, and/or professional indexers." ${ }^{\text {Access }}$ to the database would be provided by a "network [employing] fiber-optic cables in which a single fiber will be able to transmit at 50 Tbit/sec, allowing a central or regional server with a high degree of parallelism to transmit simultaneously over hundreds of channels at 100 Gbit/sec for each."7

The report asserts that this "revolution will change the very nature of libraries." It notes:

Despite the attractiveness of being able to search in a powerful and interactive way, many scientists will prefer not to be the actual searchers. This has been the frequent experience of information managers (and librarians, where they are available to do the searching). This will define an important role for the electronic-age librarian. ${ }^{9}$

The task force urges the APS and its parent body, the American Institute of Physics, to "take a leadership role in 
bringing together the [other scientific] professional societies so that ... the World Scientific Information System will be organized to provide maximum benefit to the scientific community and thus to science itself." 10

Certainly, the design identified in the APS report will be subject to much scrutiny and adjustment before an electronic world scientific information system is established; however, its basic elements provide a reasonable and even compelling model for future planning. Perhaps the most likely change will be amplification: social scientists and humanists will undoubtedly wish to participate. This, of course, will result in the creation of an electronic world scholarship information system (or systems), including all scholarly publication.

Assuming that within the next thirty years, scholarly publication becomes electronic and is dispensed through an international communication network, the primary source of the research library's present problems -its need to acquire and maintain enormous print collections-will be eliminated.

Assuming that within the next thirty years, scholarly publication becomes electronic and is dispensed through an international communication network, the primary source of the research library's present problems - its need to acquire and maintain enormous print collections-will be eliminated. In the meantime, however, research librarians must respond to two formidable challenges. First, they must begin to prepare for their electronic future. Second and more urgent, they must find means, in the face of increasing fiscal difficulty, to meet their clientele's needs while this transition takes place.

Throughout their history, research librarians have emphasized ownership. They have judged their libraries primarily by the size of their holdings, and they have influenced faculty and aca- demic administrators to do the same." As a consequence, research librarians have invested the vast majority of their resources in buying, organizing, and maintaining enormous collections.

Research librarians have relied only marginally on sharing. They have encouraged their clientele to expect to find everything, or at least almost everything, that they need on campus, in the local library collections. The result has been that, despite a good deal of talk about cooperative collection development and resource sharing, an acquisitive, competitive mentality continues to dominate research library practice. ${ }^{12}$

Of course, on-site ownership is extremely important in a print environment. Until quite recently, prompt and convenient access to needed material has been possible only if that material is held locally, and prompt and convenient access to information at need is a sine qua non for active, busy researchers. Indeed, researchers have generally insisted not only on having access to comprehensive collections, but also on having these collections housed in nearby libraries, down the hall if possible, where rows of stacks filled with volumes are expected to stand waiting for the chance use. They strongly and persistently resist any change, such as remote storage, that imposes difficulties or barriers to access. And research librarians have encouraged such expectations.

In an electronic future, such as that predicted by the APS task force, large local collections will, of course, no longer be essential. Indeed, the multimillion-volume holdings, substantially replicated in hundreds of research libraries, that are being acquired, organized, and maintained at the cost of billions of dollars annually, will become a burden rather than a benefit.

Given these circumstances, it is essential that research librarians adopt a new and radical approach to collection development. During the interim period that lies ahead, while the print distribution system of scholarly communication winds down and until the new electronic system is fully in place, research library 
acquisition should be guided by four principles:

- Purchase only those materials that, because of intensity of use, must be at hand at all times;

- Purchase lesser-used materials only if it is impossible or unduly expensive to buy or borrow them on demand;

- Purchase nothing, except special collections, on the basis of long-term speculation;

- Implement a genuine and substantial cooperative collection development program at the national level.

Research librarians should effectively begin to reverse the approach that they have followed throughout the print era: rather than buying as much as they possibly can, to respond to any present or potential need, they should acquire only the most heavily and regularly used material for processing and retention.

Instead of measuring a research library's quality according to the size of its collections and acquisition budget, both librarians and researchers must begin to evaluate its success on the basis of a single criterion: current user satisfaction. Dollars must be expended to provide the desired information resource, whether article or monograph, on demand, rather than investing in the acquisition of materials for which there is no demonstrated present need.

This is not to suggest that research librarians abdicate their historic responsibility for preserving the entire record of world scholarship. This responsibility must, however, be approached realistically for what it is: a shared obligation to be cooperatively implemented by the entire research library community rather than pursued individually and competitively by every member of that community. Wise expenditure of circumscribed funds requires that individual libraries move away from the concept of the library of record toward one that views the library as the gateway to information.

This identifies the second principle that should guide research library activity through the next several decades: prompt, effective delivery. With the implementa- tion of online catalogs, research librarians are beginning to look anew at a service that has been tried with only marginal success in the past-that is, document delivery. Research libraries that have made their new online catalogs accessible via campus networks have, in many instances, supported them with on-request delivery. Capitalizing on the speed of electronic mail, expedited handling within the library, and express delivery, some libraries have been able to set a standard of a twenty-four-hour response. ${ }^{13}$

\section{Instead of measuring a research library's quality according to the size of its collections and acquisition budget, both librarians and researchers must begin to evaluate its success on the basis of a single criterion: current user satisfaction.}

In mounting such programs, research librarians are effectively beginning a revolution in service-a revolution that can help them gradually shift their emphasis from ownership toward access. As researchers become used to getting the material that they need delivered in timely fashion to their offices, laboratories, or other appropriate "drop," they will cease to focus their attention on the desirability of massive collections in libraries that they no longer have to visit.

Of course, this change of attitude will not happen overnight. Some influential faculty may, for a considerable period of time, resist any decline in the massive local collections that they have long supported as evidence of institutional distinction. Certainly, research librarians cannot ignore or dismiss such resistance. On the other hand, they must not allow themselves to be unduly diverted or frustrated by it. Every major development in research library practice, from the classification of collections to the introduction of online catalogs, has involved some struggle of this nature, yet research libraries have progressed. ${ }^{14}$

In this instance, given the driving forces of economics and technology, 
which are increasingly visible to the entire scholarly community, necessary change cannot long be resisted, particularly if it is implemented with sensitivity. As the pace of scholarship continues to quicken and as active scholars in all fields benefit more and more from the speed and convenience of electronic mail and bulletin boards, clientele pressure on research libraries will, itself, shift from support for the slow, deliberate acquisition and processing of enormous collections to insistence on the prompt provision of needed information. ${ }^{15}$

Moreover, extensive library collections have never been an unalloyed benefit. Their very size and complexity make them exceedingly difficult to use, and drive researchers to seek alternative information sources. In fact, most researchers turn to the library only when all other avenues have been exhausted. ${ }^{16}$ Thus the critical issue for research librarians is to design and demonstrate a system that will make prompt and reliable access possible, irrespective of ownership. Once researchers are able to request every needed item with the same ease and facility, whether or not it is in their library's collections, ownership becomes irrelevant. The conditions needed to accomplish this are either presently available or relatively close at hand.

Methods of rapid information transfer have improved enormously since research librarians began to discuss the desirability of refocusing their objectives from ownership to access. Most dramatic, of course, is fax; however, the rise of commercial one-day document delivery service is at least equally important. These two services, properly used, provide a basis for effective resource sharing that was literally unimaginable twenty years ago. Hard on their heels, and promising even more fruitful benefits, is the combination of electronic text scanning and transmission, which has the potential of providing instant access to any material, regardless of distance. These developments rapidly are making it possible for research libraries to supply their clientele with materials held elsewhere, even across the country, as quickly as they can with material in their collections.

If research librarians are to reconfigure their programs in this way, however, they must make some major changes in how their libraries operate. They must certainly change their posture toward interlibrary borrowing and lending, which must be transformed from a last resort to a primary activity. They must move their resource-sharing operations out of the nooks and crannies in which they are all-too-frequently lodged and provide them with sufficient support so that they can become a viable alternative to on-site collections. Interlibrary loan deserves not only a change of name but a face-lift and a new personality. It must be overhauled, expanded, and moved front and center within research library facilities, priorities, and budgets. It must be staffed with some of the library's most effective, most serviceminded personnel.

Once researchers are able to request every needed item with the same ease and facility, whether or not it is in their library's collections, ownership becomes irrelevant.

Research librarians must be prepared to utilize every source of alternative access available, whether it is another library, the publisher, or a commercial information service. It will certainly be essential to maximize rapid and effective resource sharing among and between research libraries. This means that all research libraries must strengthen not only their borrowing but their lending operations as well. In addition, research librarians must move beyond the philosophical contemplation of cooperative collection development and make it a day-to-day reality. Declining budgets are forcing uncoordinated picking and choosing from the scholarly information universe. Collections are becoming increasingly redundant, and works of interest to only limited segments of the scholarly community are, perforce, falling between the 
cracks. The goal of individual comprehensiveness has been abandoned, and the obligation of collective coverage is increasingly at risk.

The only solution to this problem is to take a radical approach to cooperative collection development that ceases to nibble around the edges and consciously reduces, as severely as possible, the enormous redundancy that presently exists among research library acquisition programs. If research libraries' resource-sharing programs are adequately upgraded, there is no reason for a hundred institutions to buy, process, and retain several hundred copies of the same monograph or journal unless such intense duplication is justified by equally intense use.

Certainly, a document provision program of this kind will have substantial costs. How are they to be met? There is only one source available to research libraries: their acquisition budgets. If the hundred largest United States and Canadian research libraries reduced their serials expenditure by one-fifth, this would yield an average annual savings, per library, of approximately $\$ 500,000$ per year, in direct acquisition and binding costs alone, according to data published by the Association of Research Libraries. ${ }^{17}$ This amount should be sufficient to purchase, in the form of originals or photocopies, needed items on demand, including but not limited to articles in journals that had been cancelled or not acquired in order to generate these funds. Such a program would not only provide access to all of the cancelled material; it would make additional items available as well, thus extending overall access to library clientele.

Some funds for staffing this activity should be secured through the redeployment of acquisition resources. These could be supplemented by staff that would have been involved in ordering, processing, binding, maintaining, and circulating the cancelled materials; now they could redirect their energies to delivering information from external sources.

This shift of resources from document collection to document provision can be increased as research libraries extend the scope and effectiveness of off-site access, so that ultimately local collections contain only the most actively used material as well as material for which they have assumed cooperative collection responsibility. As individual research libraries are relieved of the burden of covering the entire range of scholarly publication as fully as possible, each of them will have adequate resources available to acquire and maintain everything in a few selected fields.

It might be argued that research libraries have no business, whatever the circumstances, of investing substantial and increasing shares of their budgets in materials that are given to clientele rather than added to collections. Doesn't this, somehow, violate these libraries' fundamental stewardship obligation? The answer to such an objection is that successful stewardship of the record of scholarship has two attributes: preservation and availability. If these can be achieved more effectively through a complete, distributed collection providing copies on demand, rather than through a number of highly redundant and increasingly incomplete, local-circulating collections, what does it matter that a major portion of the funding is invested in copies that are given away rather than expensively housed to meet, at best, an occasional need? Institutional fiscal officers who might object to such an approach would surely need only to be reminded that it will severely reduce every research library's future collection space requirements.

Of course, a change of this dimension will require considerable planning and coordination at the national level. It will be essential to ensure that all areas of research publication are fully covered, that there is equity in the distribution of responsibilities, that each participating library lives up to its obligations, and that resource-sharing programs are fully and effectively implemented. Such planning and coordination can certainly be accomplished by research libraries, ideally working together through their primary organization, the Association of Research Libraries. 
By such a process, but only by such a process, the long-unfulfilled prospect of a meaningful research library cooperative collection development program will be accomplished. At the same time, the longproclaimed shift in research library objectives, from emphasis on ownership to provision of access, will be achieved. There are a number of interesting possibilities that can be pursued in order to initiate and further this transformation.

Research libraries have recently begun to incorporate, in their local online catalogs, records of materials that are not among their holdings, most notably the cataloged collections of the Center for Research Libraries. Some libraries are providing access to bibliographic files, such as OCLC and RLIN and LC, that incorporate much larger collections than those held locally. As delivery is improved, both on campus and among institutions, so that clientele are able to request and receive needed items promptly and without coming to the library, local catalogs could be replaced by the larger, more comprehensive files, at least on campus electronic networks. This would radically advance the process of freeing research library clientele-and research libraries-from their dependence upon and absorption with local holdings.

Research libraries are also beginning to provide access to index databases through campus networks. Coupled with reference service via electronic mail, with which some of these libraries are also experimenting, remote access to index databases can eliminate the need for researchers to visit libraries even to carry out complex searches in the journal literature. This will only happen, however, to the degree that research librarians adopt an active posture toward reference service. They cannot simply refer remote researchers to an array of materials, particularly noncirculating reference materials whose texts are not yet online. They must be prepared to provide vigorous, aggressive information delivery, assisting clientele in their use of online sources and providing more substantive and extensive information via electronic mail.

As research librarians take steps such as these, they transform their libraries from massive repositories of stored material, gradually declining in strength and quality with every passing year, to active service centers, drawing on all available resources to meet the information needs of their clientele. They also begin to establish their essential role in the electronic future, where international information systems will maintain the entire record of scholarship online, instantly accessible to campus information centers throughout the world.

\section{REFERENCES AND NOTES}

1. Anthony DePalma, "Hard Times Force Many Universities to Rethink Roles," New York Times, Feb. 3, 1992, A1, A12.

2. "Budget Crises in ARL Libraries: Strategies for Managing Finances and Services," in Association of Research Libraries, Minutes of the 118th Meeting (Washington, D.C.: ARL, 1991), 51-56.

3. Ibid.

4. "Report of the APS Task Force on Electronic Information Systems," American Physical Society, Bulletin 36:1119-51 (Apr. 1991), 1137. See also 1131: "The description is necessarily speculative and vague, but we don't think it is unduly optimistic; the seeds for most of what we describe are already planted. If anything, this asymptotic state may be reached by the year 2000 or 2010 . By 2020 we may have moved on in unpredictable ways."

5. Ibid. 1140. This issue has received wide discussion in the literature on scholarly communication over the past several decades. Perhaps the most up-to-date analyses, all prepared by Constance Gould for the Research Libraries Group, are: Constance C. Gould, Information Needs in the Humanities: An Assessment (Stanford, Calif.: Research Libraries Group, 1988); Constance C. Gould, Information Needs in the Social Sciences: An Assessment (Mountain View, Calif.: Research Libraries Group, 1989); and Constance C. 
Gould, Information Needs in the Sciences: An Assessment (Mountain View, Calif.: Research Libraries Group, 1991).

6. Ibid. 1134.

7. Ibid. 1130 .

8. Ibid. 1138.

9. Ibid. 1135.

10. Ibid. 1139.

11. David Kaser, "Collection Building in American Universities," in University Library History: An International Review, ed. James Thompson (New York: K. G. Saur, 1980), 33-55.

12. Joseph J. Branin, "Cooperative Collection Development," in Collection Management: A New Treatise, ed. Charles B. Osburn and Ross Atkinson (Greenwich, Conn.: JAI, 1991), 81-110.

13. Such a program is presently being offered at the University of Minnesota-Twin Cities Campus Libraries. At present, the service is limited to faculty and researchers with campus addresses.

14. Seymour Lubetsky," "Ideology of Bibliographic Cataloging: Progress and Retrogression," in The Nature and Future of the Catalog: Proceedings of the ALA's Information Science and Automation Division's 1975 and 1977 Institutes on the Catalog, ed. Maurice J. Freedman and S. Michael Malinconico. (Phoenix, Ariz.: Oryx, 1979). This article recounts the struggle, a century and a half ago, between the librarian of the British Museum and a group of noted scholars over implementation of a classed catalog for the museum's collection.

15. N. David Mermin, "Publishing in Computopia," Physics Today 44(May 1991): 9,11. It is interesting to note that for every library user - student, faculty member, researcherwho complains about the switch from card catalog to online file, there are many more who chaff at the present limitations of such files: the lack of inclusion of all local holdings, the absence of references to journal articles, etc. Conversely, some research librarians have resisted incorporating any records in their online catalogs for anything not owned by their libraries. Attitudes must be changed in a variety of quarters.

16. Eldred Smith, The Librarian, the Scholar, and the Future of the Research Library (Westport, Conn.: Greenwood, 1990), 19-25.

17. ARL Statistics, 1989-90 (Washington D.C.: Association of Research Libraries, 1991). These reductions must, of course, be made in addition to any acquisition reductions that research libraries are forced to make because of a diminution in their available resources. The objective is to generate funds necessary to support programmatic change. Without such an effort, research libraries confront the possibility of a "death by one thousand cuts" - the gradual elimination of their effectiveness through a slow sapping of funding. 